\title{
Researching Formal and Informal Learning: From Dichotomies to a Dialogic Notion of Learning
}

Kumpulainen, Kristiina

2015-11-01

Kumpulainen, K \& Mikkola , A 2015 , ' Researching Formal and Informal Learning: From

Dichotomies to a Dialogic Notion of Learning ' , International Journal for Research on

Extended Education , vol. 3 , no. 2 , pp. 5-23 . https://doi.org/10.3224/ijree.v3i2.20889

http://hdl.handle.net/10138/232908

https://doi.org/10.3224/ijree.v3i2.20889

publishedVersion

Downloaded from Helda, University of Helsinki institutional repository.

This is an electronic reprint of the original article.

This reprint may differ from the original in pagination and typographic detail.

Please cite the original version. 


\title{
Researching Formal and Informal Learning: From Dichotomies to a Dialogic Notion of Learning
}

\author{
Kristiina Kumpulainen \& Anna Mikkola
}

\begin{abstract}
This article is situated in a body of research focusing on learning in and out of school, often referred to as studies of formal and informal learning. Drawing on the dialogic approach, the article warns against simplistic and dichotomous definitions of what counts as formal and informal learning. Instead, it calls for the importance of understanding learning as a dialogue between contexts of discourse in which the attributes of "formality" and "informality" intersect. By taking discourse as the core unit of analysis, the approach advocated here focuses on examining how students' discourses embedded in diverse contexts are managed, negotiated, and hybridized during their academic work. We shall exemplify our argument with empirical data stemming from a case study on elementary school students' online interaction during creative collaborative writing. In our analysis of the data, we illuminate the hybridization of students' online interaction in which diverse contexts of discourse come into dialogue, producing opportunities and tensions for their engagement, learning, and identity. The article finishes by considering the wider implications of the dialogic approach to understanding learning across contexts.
\end{abstract}

Keywords: formal and informal learning environments, sociocultural approach, hybrid space, dialogic learning

\section{Introduction}

The discontinuities between in and out of school learning have been the source of robust scholarship since the early 20th century (Dewey, 1916; Kilpatrick, 1923, 1925). In her seminal work, Lauren Resnick (1987) illuminated discrepancies in students' learning across settings, illustrating how school learning is typically characterized by focus on individual performance, symbolic thought, as well as general skills and knowledge. Out-of-school learning, on the other hand, is mostly socially shared; tool-aided; and embedded in mediating objects, resources, and situations, resulting in contextualized competencies, skills, and knowledge practices (Resnick, 1987).

Examinations of the discrepancies between learning in and out of school have been enriched by more recent research that addresses the changing role of digital technologies and media in shaping the ways in which young people engage, learn, and build their identities. Research has demonstrated that informal digital learn- 
ing practices are often highly social, characterized by various forms of self- and/or peer-teaching (Willet \& Sefton-Green, 2002). Moreover, these practices are found to be typically self-initiated and self-motivated, evidencing a strong sense of agency on the part of learners.

While contrasts between the dominant features of learning in the formal institutional settings of the school and in more informal settings of everyday life are valuable in extending our understanding of the nature and conditions of learning in diverse sociocultural contexts, in this article, we argue that approaching learning in formal and informal settings dichotomously has limitations that may lead to fragmentation, stereotyping, and oversimplification (Bowker \& Star, 1999; Colley, Hodkinson, \& Malcolm, 2003).

Drawing on the dialogic approach, the goal of the article is to offer an alternative conceptual framing that does not regard contexts as backgrounds but rather as being produced, negotiated, and hybridized in social interaction, creating varying opportunities for students' engagement, learning, and identity (Leader, 2001). By taking discourse as the core unit of analysis, the approach advocated here focuses on examining how students' discourses embedded in diverse contexts are managed, negotiated, and hybridized during their academic work. Such an approach allows us to recognize changes to student engagement, learning, and identity when the balance between various discourses shifts in evolving social interactions.

We exemplify our argument with empirical data stemming from a case study on elementary school students' online interaction during creative collaborative writing. In our analysis of the data, we aim to illuminate the hybridization of students' online interaction in which diverse discourses meet, producing opportunities and tensions for their engagement, learning, and identity. The article finishes by considering the wider implications of the dialogic approach to understanding learning across contexts.

\section{The Dialogic Approach}

The dialogic approach to learning discussed in this article is guided by sociocultural theories (Cole, 1996; Kumpulainen \& Renshaw, 2007; Vygotsky, 1978). The dialogic approach focuses on social interactions that emerge in horizontal movement as we draw upon multiple contexts, including peer relations, family, and school, to make meaning with others (Barron, 2006; Gutiérrez, Baquedano-López, \& Tejeda, 1999). By viewing context as a function of the dynamic interaction between multiple layers of activity, the dialogic view foregrounds that during joint engagement, participants are active in creating social and interactional contexts (Goffman, 1974; Kumpulainen \& Mutanen, 1999; Schubauer-Leoni \& Grossen, 1993). From this standpoint, interaction is not determined by the medium or physical context; rather, it is negotiated dynamically in social interaction. Social interaction is performative and context-transforming, facilitating the ongoing negotiation of meaning and presentation of self (Thorne, 2003). 
Instead of conceptualizing learning merely as an epistemic process, in the dialogic approach, learning is considered as inseparably linked with existential and socio-emotional processes involved in transforming identities and developing agency (Packer \& Goicoechea, 2000). It focuses on understanding how identities are locally and interactionally constructed and on shifts in relation to the social setting and actors (Hand, 2006; Holland, Lachiotte, Skinner, \& Cain, 1998; Nasir \& Saxe, 2003). Here, identity is examined from the ways in which one is positioned and positions oneself in the moment and over time across social practices (Holland, Lachiotte, Skinner, \& Cain, 1998).

\section{Discourse as a unit of analysis}

The core analytic unit in our approach to unpack the production, negotiation, and hybridization of multiple contexts in social interaction is discourse (Gee, 2010). Discourses are enacted through the practices of the communities in which people participate (Wenger, 1998). They offer membership in communities that involve ways of being, valuing, and speaking. Gee referred to such memberships as identity kits (1996), situated identities (2010), and affinity groups (2001). Discourses are considered to be an integral part of value- and belief-laden practices that are lived, talked, enacted, and carried out in specific places and at specific times (Gee, 1996). It follows that discourses can be understood only within the sociocultural context in which they originate (Gee, 2010).

In our approach, we are specifically interested in the notion of "hybrid" space that can be achieved when diverse discourses embedded in young people's multiple life worlds intersect (Bhabha, 1994; Gutiérrez et al., 1999). According to Gee (2010), a hybrid space is where pupils' primary discourses, which are used in the home, community, and informal social interactions, and pupils' secondary discourses, which are endorsed by school and other formal institutions, intersect to form a subsequent "in-between" space. In this space, oppositional categories work together to open up different possibilities for student engagement, learning, and identity. A hybrid space can thus be both productive and constraining in terms of engagement and learning, and, ultimately, sense of self and belonging (Bhabha, 1994).

\section{Empirical Study}

Next, we exemplify our approach to researching learning as a dialogue between contexts of discourse by drawing on empirical data stemming from a case study on elementary school students' online interaction during creative collaborative writing. In our analysis of the data, we illuminate the hybridization of students' online interaction in which diverse discourses come into dialogue, producing opportunities and tensions for engagement, learning, and identity. The empirical research discussed in the article has been reported more substantially in other publications (see Kumpulainen, Mikkola, \& Jaatinen, 2013; Kumpulainen \& Mikkola, 2014). 


\section{Research setting}

The data are derived from a case study of a yearlong school musical project in a Finnish primary school community of 240 students (grade levels one through six) and 16 teachers in the Helsinki district. All students in the school participated in a communal musical production, and during a period of one year, worked together with their teachers and collaboratively produced a number of poems, short movies, audio-visual effects, animations, stories, a school musical script, and a composition of the musical melody using various technological tools and devices. The outcome of the students' work, the fantasy school musical "Magic Forest Musical," was performed on the anniversary of the school's founding. The musical production was an integral part of the official curriculum of the school and not an extra addition.

The data discussed here come from a three-month phase in the musical project during which 21 fifth- and sixth-grade students (ages 11 to 12) took part in writing the school musical script. The students worked in 10 small, self-selected teams of two to three students, with each team writing one part of the script. To enable the students' collaborative creation of the script in and outside of school, they were given small, one-to-one computers set up with a 24-hour wireless Internet connection. The laptops were equipped with a collaborative writing tool called VisciPad, which included a chat channel. VisciPad enabled students to simultaneously edit the same text document, that is, work in real time.

The students were allocated two one-hour sessions every week to write the script at school. The teams were able to organize their writing as they wished without any prefixed daily schedules or teacher control. The only obligation was that the scripts had to be completed within the three-month time period for the musical project to proceed. As a final result of the project, the students produced 14 different scripts; some were relatively short, for instance, those to be performed by second graders, some had music and lyrics, and others had more dialogue.

\section{Data analysis}

The data we draw upon derive from the students' online chat discussions $(\mathrm{N}=4,744)$; these were messages they exchanged during the collaborative writing of the school musical script. The methodology guiding our analysis is based on educational linguistics, namely, interactional sociolinguistics (Gee, 1996) and ethnography of communication (Gumperz, 1982), which examine language as inseparable from the contexts of its use. In our analysis, we focus both on the content and organization of the students' evolving chat interaction. We paid specific attention to the contexts of the students' discourses and how these contexts are negotiated and managed in evolving online interaction (Bloome \& Clark, 2006). 


\section{Illustrative Cases}

Our analysis of the data reveals dynamic interaction between multiple contexts of discourse in the students' chat interaction during creative collaborative writing. The students produced and negotiated discourses that were related to their joint composition of the musical script, including planning, revising, and evaluating. These discourses were managed in dialogue with other discourses that specifically dealt with the students' socio-emotional work. Characteristic to these socio-emotional discourses was the students conveying their social presence to others, a necessary condition for collaborative work in online interaction (Gunawardena, 1995). The students' discourses also entailed playful interactions in which they gave supportive feedback to each other and asked for help in creating text and in using the technology. In addition, the students' socio-emotional discourses carried information about their state of mind and mood. Typical moods included expressions of being happy and positive and, likewise, expressions of being bored or tired. Here, the use of various forms of expression of emotions, including emoticons, repetitious punctuation, and conspicuous capitalization, was also evident.

Table 1. Playful Evaluation of Joint Writing

\begin{tabular}{|l|l|}
\hline Chat Interaction & Contexts of Discourse \\
\hline March 4 & \\
1: Minna: Hiii & \\
2: Aino: Hahaa.... I corrected a spelling mistake!!.D & Evaluation of \\
3: Outi: ye, well that's okay & joint writing \\
4: Outi: I mean yes & Establishing \\
5: Satu: hi I found my way here so I left a footprint:)) & mutual presence \\
March 5 & Playful \\
6: Outi: :) (11:37) & interaction \\
7: Elli: hi (12:50) & Asking for help \\
March 6 & \\
8: Tanja: I need ideas! & \\
March 7 & \\
9: Satu: morning;) How can I make a heart with this & \\
computer? & \\
10: Elli: öööö dunno & \\
March 11 & \\
11: Elli: A piece of music from a record & \\
March 12 & Establishing \\
12: Aino: Hi Sannanen and everyone else! It is a bit lonely & mutual presence \\
here. halloo!! & \\
March 15 & Evaluation of \\
13: Suski: hi sannaaaaa.... it seems that this is progressing & joint writing \\
well=) & \\
March 16 & \\
14: Satu: looks good & \\
March 21 & \\
15: Elli: Thanks & \\
April 4 & \\
16: Suski: hellou, looks good!!! who teaches all the tricks to & \\
those guys??? or are they now so clever that they already & \\
know everything?????? & \\
\hline & \\
\hline
\end{tabular}


The extract shown in Table 1 illustrates how socio-emotional discourses, such as playful use of language, in the students' chat interaction were an integral part of their collaborative writing activity. Seemingly, the students also engaged in thoughtful discussions about the nature and progress of their joint script for the school musical: They evaluated their collective work, gave supportive feedback to each other, and asked for help in creating text and in using the technology. All these discourses and their dialogue in ongoing chat interaction are important elements of productive creative collaboration and learning (Dillenbourg, 1999; Moran \& John-Steiner, 2004).

In addition to discourses related to the joint writing activity and socio-emotional work, the students' chat interaction produced a context in which the students talked about their exams, homework, school lunch, and break time. They also shared their music and movie preferences, hobbies, food, travels, mundane observations of their living environment, and recent news covered by the media. Although the discourses of the students' local, everyday experiences and knowledge are not usually recognized or valued in the official script of schooling (Gutiérrez, Larson, \& Kreuter, 1995), they appeared to play an important role here, supporting the students' joint creation of the musical script and strengthening mutual understanding and trust between the students.

The extract in table 2 illustrates how the students' active engagement in their joint writing activity interacted with the students sharing their music preferences. The extract begins by Sofia's two messages sent immediately after each other. In line 107, she asks Megan for her opinion on how to continue with their writing. In her next message (line 108), she queries Megan's music preferences. Megan responds to both of these initiations, and the students negotiate and manage the interplay of these different contexts of discourse in their evolving dialogue.

Table 2. Joint Writing Activity Interacts With Sharing Music Preferences

\begin{tabular}{|l|l|}
\hline Chat Interaction & Contexts of Discourse \\
\hline April 1 & \\
107: Sofia: How should we do this then & Joint writing \\
108: Sofia: And what are you listening to & Querying music \\
109: Megan: well, should we write the lines with the other & preferences \\
class since it would be cool if they could also create them & Joint writing \\
110: Megan: Cool pieces :D & Sharing music \\
111: Sofia: ok & preferences \\
112: Sofia: name???? & Joint writing \\
113: Megan: There it was & \\
114: Megan: h0h00 & \\
115: Sofia: well, should we start to create those lines (to & \\
start with) minute by minute!!!! or???? & \\
116: Sofia: let's say that we'll prefer to do it with that & \\
class since otherwise we could not get it ready & \\
117: Sofia:? & \\
118: Sofia: Do you agree? & \\
\hline
\end{tabular}

The extract in Table 3 illuminates the students Enni and Pinja sharing their experiences and concerns about school exams. The extract reflects the pressures the students experience in getting high grades and fulfilling the expectations of others. Here, the discourse departs from the actual writing activity, serving yet another important function, that is, the students sharing their concerns about the requirements of the 
school and how they cope with them. We can also identify the students engaging in negotiating their identities as students.

Table 3. Coping With the School

\begin{tabular}{|c|c|c|}
\hline \multicolumn{2}{|c|}{ Chat Interaction } & \multirow[t]{2}{*}{ Contexts of Discourse } \\
\hline March 13 & & \\
\hline 134: (9:15) & $\begin{array}{l}\text { Pinja: I'm afraid of the math exam. } \\
\text { It went so badly from me! }\end{array}$ & Coping with the math exam \\
\hline 135: (9:16) & Enni: no it didn't & \\
\hline 136: (9:16) & $\begin{array}{l}\text { Pinja: Especially the last page. I } \\
\text { know I have lost at least two points! }\end{array}$ & \\
\hline 137: (9:16) & Pinja: mimimimimiiiiii... & \\
\hline 138: $(9: 16)$ & Pinja: history exam? & \\
\hline 139: $(9: 16)$ & $\begin{array}{l}\text { Pinja: do you remember what you } \\
\text { got from it? }\end{array}$ & Comparing exam results \\
\hline 140: $(9: 17)$ & Enni: $=($ & \\
\hline 141: (9:17) & Pinja: did we loose the connection? & Establishing mutual presence \\
\hline 142: $(9: 17)$ & Enni: no & \\
\hline 143: (9:17) & Pinja: so? & \\
\hline 144: $(9: 17)$ & Pinja: what took so long what $=($ & \\
\hline 145: $(9: 18)$ & $\begin{array}{l}\text { Enni: I know that at least two } \\
\text { problems went badly }\end{array}$ & \\
\hline 146: $(9: 18)$ & Enni: I am a slow writer & Identity as a "slow writer" \\
\hline 147: (9:18) & Pinja: oh no. & \\
\hline 148: $(9: 18)$ & Pinja: ok & \\
\hline 149: (9:18) & Pinja: they were easy & \\
\hline 150: (9:18) & Enni: yeah but I did not think enough & \\
\hline 151: (9:19) & Pinja: poor you. & \\
\hline 152: (9:19) & Pinja: you don't have any pressures! & \\
\hline 153: (9:19) & Enni: I marked $60 \%$ to the fourth thing. & Being accountable to others \\
\hline 154: (9:19) & Enni: how come you don't have & about success at school \\
\hline 155: (9:19) & $\begin{array}{l}\text { Pinja: so if I don't get more than nine } \\
\text { I feel that I have betrayed someone... }\end{array}$ & \\
\hline 156: (9:19) & Pinja: that maybe you also have;) & \\
\hline 157: (9:19) & Enni: yeh well but my math number is eight & Comparing math achievement \\
\hline 158: $(9: 20)$ & $\begin{array}{l}\text { Pinja: well but let's not bother talking } \\
\text { about the school }\end{array}$ & \\
\hline 159: $(9: 20)$ & Pinja: especially about maths! & \\
\hline 160: $(9: 20)$ & Enni: so that there are no pressures & \\
\hline
\end{tabular}

The extract shown in Table 3 demonstrates how the interplay of various discourses in the students' chat interaction also creates tensions for the students to maintain their joint focus of attention on their writing activity. The tensions showcase how "hybrid" spaces accomplished by the interplay of diverse discourses require and afford continuous negotiation and attention from participants. On the other hand, negotiating tensions appeared to contribute to building a positive affective structure, thus building a sense of belonging and community (Kreijns, Kirschner, \& Jochems, 2003). 


\section{Discussion}

This article is situated in a body of research focusing on learning in and out of school, often referred to as studies of formal and informal learning. Drawing on the dialogic approach, the article has called for the importance of understanding learning as a dialogue between contexts of discourse in which the attributes of "formality" and "informality" intersect. In doing so, it has warned against simplistic and dichotomous definitions of what counts as formal and informal learning. We have explained our approach with empirical data stemming from a case study on elementary school students' online interaction during creative collaborative writing. In our analysis of the data, we have illuminated the hybridization of students' online interaction in which diverse contexts of discourse come into dialogue, producing opportunities and tensions for their engagement, learning, and identity.

Our study demonstrates how students' discourses and educational engagement in general were simultaneously nuanced and coherent, ambivalent and confused. The educational engagement identified broke away from the typical tightly defined and teacher-controlled learning activities that often silence more emotional and/or everyday discourses of the students (Kumpulainen \& Mikkola, 2014). Here, the students' joint creative activity was distributed across several contexts, reflecting educational engagement where discourses that are often marginalized in formal schooling became visible. Hence, the students' learning activity could be characterized as situated within a matrix of multiple sociocultural contexts (Lantz-Andersson, Vigmo, \& Bowen, 2013; Ramsten \& Säljö, 2012).

The data demonstrate how the students' various discourses intersected, overlapped, and coexisted at different points in time and space (Barron, 2004, 2006). As students engaged in such "hybrid" spaces (Bhabha, 1994), they were co-constructing the cultural practices of what it means to participate and learn at school, thus also building their identities. Here, the students used various discourses to adopt and adapt extant discourse practices in their meaning-making as they defined their social relationships, social identities, and knowledge. It was in these "hybrid" spaces in which the multidimensionality of learners' identities came into play and in which new social practices emerged (Akkerman \& van Eijck, 2013). The different discourses and their hybridization in the students' chat interaction appeared to support joint creative writing in several ways, such as establishing a common ground and negotiating responsibilities and shared commitment for collaborative work. The interplay of discourses also resulted in a space for the students' social construction of mutual inspiration and trust (Kumpulainen \& Mikkola, 2014).

Our empirical case also demonstrates how sometimes competing discourses intersected in the students' chat interaction. These discourses and the tensions they created both reshaped and challenged the students' engagement in their collaborative creative learning activity. Moreover, these tensions showcase how maintaining a "hybrid" space requires and affords continuous attention from participants. This also underscores the important role of educational conditions in supporting sustained and productive engagement and learning toward valued educational goals (Kumpulainen, 2013). It can be concluded that the hybridity evidenced in this study ruptures the 
dominant idealization of formal education that seeks predictability and uniformity as well as narrowly defined notions of what counts as 21 st-century educational engagement and learning.

\section{Directions for Future for Research}

Approaches to learning that address the interplay of contexts of discourse in social interaction raise several research questions that call for attention. Clearly, future research needs to investigate the degree to which the interplay of various contexts of discourse promotes students' engagement in learning and identity-building in different types of educational settings and among students and teachers. Future investigations also need to address the mechanisms of "hybrid" learning among diverse students and seek to identify and redefine learning supports and outcomes.

Lastly, while the interrelationships between various discourses can be examined in terms of situationally constructed micro-level activities in classroom communities, whether online or offline, it is essential to also address meso- and macro-levels of activity. This investigation can further our understanding of the wider sociocultural contexts that interact with students' engagement, learning, and identity in a given social setting, including its processes, purposes, and content of activity. Such inquiry can lead to highly relevant societal and political questions, such as the emancipatory potential of formal education in contemporary society.

\section{References}

Akkerman, S., \& van Eijck, M. W. (2013). Re-theorising the student dialogically across and between boundaries of multiple communities. British Educational Research Journal, 39(1), 60-72.

Barron, B. (2004). Learning ecologies for technological fluency: Gender and experience differences. Journal of Educational Computing Research, 31(1), 1-36.

Barron, B. (2006). Interest and self-sustained learning as catalysts of development: A learning ecology perspective. Human Development, 99, 193-224.

Bhabha, H. (1994). The location of culture. London and New York: Routledge.

Bloome, D., \& Clark, C. (2006). Discourse-in-use. In J. Green, G. Camilli, \& P. B. Elmore (Eds.), Handbook of complementary methods in education research (pp. 227-242). Mahwah, NJ: Erlbaum.

Bowker, G. C., \& Star, S. L. (1999). Sorting things out: Classification and its consequences. Cambridge, MA: MIT Press.

Cole, M. (1996). Culture in mind. Cambridge, MA: Harvard University Press.

Colley, H., Hodkinson, P., \& Malcolm, J. (2003). Informality and formality in learning: A report for the Learning and Skills Research Centre. University of Leeds. 
Dewey, J. (1916). Democracy and education: An introduction to the philosophy of education. New York: Free Press.

Dillenbourg, P. (Ed.). (1999). Collaborative learning: Cognitive and computational approaches. Amsterdam: Pergamon.

Gee, J. P. (1996). Social linguistics and literacies: Ideology in discourses. London, England: Taylor \& Francis.

Gee, J. P. (2000). Teenagers in new times: A new literacy studies perspective. Journal of Adolescent and Adult Literacy, 43(5), 412-423.

Gee, J. P. (2001). Identity as an analytic lens for research in education. Review of Research in Education, 25, 99-125.

Gee, J. P. (2004). Situated language and learning: A critique of traditional schooling. New York: Routledge.

Gee, J. P. (2010). An introduction to discourse analysis: Theory and method. New York: Routledge.

Goffman, E. (1974). Frame analysis: An essay on the organization of experience. New York, NY: Harper \& Row.

Gumperz, J. J. (1982). Discourse strategies. Cambridge, England: Cambridge University Press.

Gunawardena, C. N. (1995). Social presence theory and implications for interaction and collaborative learning in computer conferences. International Journal of Educational Telecommunications, 1(2/3), 147-166.

Gutiérrez, K., Baquedano-López, P., \& Tejeda, C. (1999). Rethinking diversity: Hybridity and hybrid language practices in the thirdspace. Mind, Culture, and Activity, 6, 286-303.

Gutiérrez, K., Larson, J., \& Kreuter, B. (1995). Cultural tensions in the scripted classroom: The value of the subjugated perspective. Urban Education, 29(4), $410-442$.

Hand, V. (2006). Operationalizing culture and identity in ways to capture the negotiation of participation across communities. Human Development, 49(1), 36-41.

Holland, D., Lachicotte, W., Skinner, D., \& Cain, C. (1998). Identity and agency in cultural worlds. Cambridge: Harvard University Press.

Kilpatrick, W. H. (1923). Source book in the philosophy of education. New York: Macmillan.

Kilpatrick, W. H. (1925). Foundations of method. New York: Macmillan.

Kreijns, C. J., Kirschner, P. A., \& Jochems, W. M. G. (2003). Identifying the pitfalls for social interaction in computer-supported collaborative learning environments: A review of the research. Computers in Human Behavior, 19, 335-353.

Kumpulainen, K. (2013). The legacy of productive disciplinary engagement. International Journal of Educational Research, 64, 215-220.

Kumpulainen, K., \& Mikkola, A. (2014). Boundary crossing of discourses in chat interaction during creative collaborative writing. Learning, Culture and Social Interaction. doi:10.1016/j.lcsi.2013.12.002

Kumpulainen, K., \& Mutanen, M. (1999). The situated dynamics of peer group interaction: An introduction to an analytic framework. Learning and Instruction, 9, 449-474. 
Kumpulainen, K., \& Renshaw, P. (2007). Cultures of learning. International Journal of Educational Research, 46(3-4), 109-115.

Kumpulainen, K., Mikkola, A., \& Jaatinen, A.-M. (2013). The chronotopes of technology-mediated creative learning practices in an elementary school community. Learning, Media and Technology. doi:10.1080/17439884.2012.752383

Lantz-Andersson, A., Vigmo, S., \& Bowen, R. (2013). Crossing boundaries in Facebook: Students' framing of language learning activities as extended spaces. Computer Supported Collaborative Learning, 8, 293-312.

Leander, K. (2001). "This is our freedom bus going home right now". Producing and hybridizing space-time contexts in pedagogical discourse. Journal of Literacy Research, 33(4), 637-679.

Moran, S., \& John-Steiner, V. (2004). How collaboration in creative work impacts identity and motivation. In D. Miell \& K. Littleton (Eds.), Collaborative creativity: Contemporary perspectives (pp. 11-25). London, England: Free Association Books.

Nasir, N. S., \& Saxe, G. (2003). Ethnic and academic identities: A cultural practice perspective on emerging tensions and their management in the lives of minority students. Educational Researcher, 32(5), 14-18.

Packer, M. J., \& Goicoechea, J. (2000). Sociocultural and constructivist theories of learning: Ontology, not just epistemology. Educational Psychologist, 35(4), 227-241.

Ramsten, A. C., \& Säljö, R. (2012). Communities, boundary practices and incentives for knowledge sharing? A study of the deployment of a digital control system in a process industry as a learning activity. Learning Culture and Social Interaction, 1, 33-44.

Resnick, L. B. (1987). Learning in school and out. Educational Researcher, 16(9), $13-20$.

Thorne, S. L. (2003). Artifacts and cultures-of-use in intercultural communication. Language Learning and Technology, 7(2), 38-67.

Vygotsky, L. S. (1978). Mind in society: The development of higher mental processes. M. Cole, V. John-Steiner, \& E. Souberman (Eds.). Cambridge, MA: Harvard University Press.

Wenger, E. (1998). Communities of practice: Learning, meaning and identity. Cambridge: Cambridge University Press.

Willett, R., \& Sefton-Green, J. (2002). Living and learning in chatrooms. Éducation et Sociétés, 10, 57-77. 